\title{
Composição Bromatológica e Digestibilidade in Vitro da Matéria Seca de Silagens de Milho e Sorgo Tratadas com Inoculantes Microbianos ${ }^{1}$
}

\section{Almir Vieira Silva ${ }^{2}$, Odilon Gomes Pereira ${ }^{3}$, Rasmo Garcia ${ }^{3}$, Sebastião de Campos Valadares Filho $^{3}$, Paulo Roberto Cecon ${ }^{4}$, Célia Lúcia de Luces Fortes Ferreira ${ }^{5}$}

RESUMO - Avaliaram-se a composição bromatológica e a digestibilidade in vitro da matéria seca (DIVMS) de silagens de milho e sorgo, tratadas ou não com inoculantes microbianos, em diferentes períodos de fermentação. Utilizou-se um arranjo fatorial 6 x 2 x 3 (períodos de fermentação x silagens x inoculantes), em delineamento inteiramente casualizado, para avaliação dos teores de matéria seca (MS) e proteína bruta (PB), e um arranjo fatorial 4 × 2 × 3 para avaliação dos constituintes fibrosos e da DIVMS, ambos com três repetições. Observou-se os efeitos da interação período de fermentação $\times$ silagem $\times$ inoculante sobre os teores de MS e da interação inoculante $\times$ período, sobre os teores de PB das silagens. Constatou-se efeito da interação tríplice também sobre os teores de fibra em detergente neutro (FDN) e fibra em detergente ácido (FDA). Estimaram-se teores mínimos de FDN nas silagens de milho tratadas com os inoculantes Silobac e MaizeAll, respectivamente, de 52,14 e 50,75\%, aos 37,34 e 46,1 dias após a ensilagem. Quanto à celulose, verificou-se, entre as silagens de milho, menores valores nas silagens tratadas, mas não foi detectado efeito de inoculante nas silagens de sorgo. Os teores médios de hemicelulose foram influenciados por silagem, período e inoculante, registrando-se na silagem de milho (29,8\%) valor maior que na de sorgo (28,4\%). Houve efeito quadrático do período de fermentação sobre a DIVMS da silagem de milho tratada com os inoculantes Silobac e Maize-All, estimando-se valores máximos de 71,1 e 71,7\%, aos 42,29 e 50,3 dias de ensilagem, respectivamente. As DIVMS das silagens de sorgo, no entanto, não foram influenciadas pelo período de fermentação.

Palavras-chave: celulose, fibra em detergente ácido, fibra em detergente neutro, hemicelulose, matéria seca, proteína bruta

\section{Chemical Composition and "In Vitro" Dry Matter Digestibility of Corn and Sorghum Silages with and without Microbial Inoculants}

\begin{abstract}
The chemical composition and in vitro dry matter digestibility (IVDMD) of corn and sorghum silages with and without microbial inoculants after several fermentation periods were evaluated in laboratory silos. A 6 × 2 × 3 factorial treatment combination (6 fermentation periods $\mathrm{x} 2$ silages $\mathrm{x} 3$ inoculants) was assayed in a completely randomized design to evaluate the dry matter (DM) and crude protein $(\mathrm{CP})$ contents and a $4 \times 2 \times 3$ factorial arrangement of treatments ( 4 fermentation periods $\times 2$ silages $\times 3$ inoculants) to evaluate the fiber constituents and IVDMD; in either case, there were three replications. Fermentation periods $\times$ silage $\times$ inoculant and inoculant $\times$ period interactions were observed for silage DM and CP silage contents, respectively. The neutral (NDF) and acid detergent fiber (ADF) had a triple interaction effect. Minimum NDF contents of 52.14 and 50.75\% were observed in corn silage inoculated with Silobac and Maize-All inoculants, respectively. Corn silage with microbial inoculant showed lower cellulose content than the untreated silages. However, there was no inoculant effect on cellulose content in sorghum silage. The mean value of hemicelullose content was affected by silage, period and inoculant, higher value being observed in corn silage (29.8\%) than in sorghum silage (28.4\%). The IVDMD of corn silages treated with Silobac and Maize-All inoculants, increased quadratically with fermentation period, showing maximum values of 71.1 and $71.7 \%$ after 42.29 and 50.3 days of fermentation, respectively. IVDMD of sorghum silage was not influenced by fermentation period.
\end{abstract}

Key Words: acid detergent fiber, cellulose, crude protein, dry matter, hemicelullose, neutral detergent fiber

\section{Introdução}

A preservação dos nutrientes das plantas ensiladas fornecidas aos ruminantes depende de vários fatores. Imediatamente após a colheita e picagem da planta, iniciam-se modificações químicas, que serão ainda mais pronunciadas com o fechamento do silo. Nestas condições, a planta é submetida a diversas transformações que se relacionam principalmente com o conteúdo de matéria seca da forragem e com o tipo de fermentação presente no silo (Pettit, 1999). Algumas perdas de nutrientes são consideradas evitáveis e, por

\footnotetext{
${ }^{1}$ Parte da tese de Doutorado em Zootecnia apresentada à UFV pelo primeiro autor, parcialmente financiada pela FAPEMIG.

2 Professor, Inst. de Produção e Saúde Animal, Univ. Federal Rural da Amazônia-UFRA Cx. Postal: 917, Belém-PA, 66077-530. E.mail: almir.silva@ufra.edu.br

${ }^{3}$ Professor, Departamento de Zootecnia - Universidade Federal de Viçosa-UFV 36571-000, Viçosa, MG. Bolsista do CNPq. E.mail: odilon@ufv.br

${ }^{4}$ Professor, Departamento de Informática - UFV, CEP: 36571-000, Viçosa, MG.

${ }^{5}$ Professora, Departamento de Tecnologia de Alimentos - UFV, CEP: 36571-000, Viçosa, MG.
} 
isso, a eficiência de sua preservação estará relacionada principalmente ao rápido enchimento do silo e à sua correta vedação, condições fundamentais para que o rápido estabelecimento da anaerobiose ocorra, sem elevação.

Vários aditivos de silagem vêm sendo utilizados nas duas últimas décadas com o objetivo de proporcionar condições favoráveis à máxima recuperação da energia deste alimento, com subseqüente ganho no desempenho animal. Entre esses aditivos, os inoculantes microbianos representam importante ferramenta, pois, segundo Henderson (1993), contribuem para a redução da proteólise enzimática, advinda da rápida queda do $\mathrm{pH}$ dentro do silo, o que favorece a produção de grandes quantidades de ácido lático, e representam, por isso, a possibilidade de maior recuperação de matéria seca.

Porém, segundo Muck (1996), o uso de inoculantes microbianos poderá também apresentar efeito negativo na conservação da silagem após a abertura do silo se os teores de carboidratos solúveis residuais forem elevados, criando-se condições favoráveis para atuação de microrganismos aeróbicos indesejáveis, como ocorre com as leveduras. Assim, o uso de inoculantes microbianos pode influenciar leve ou intensamente a ação dos microrganismos indesejáveis, dependendo das alterações finais do $\mathrm{pH}$, do conteúdo de açúcares residuais e dos ácidos lático e acético.

O sucesso no uso do inoculante microbiano está vinculado a três fatores: população natural de bactérias láticas; conteúdo de açúcares da forragem; e cepas de bactérias presentes no inoculante. A bactéria que constitui o inoculante deve ser eficiente na competição com a flora microbiana natural da planta, devendo ainda ser efetiva no processo fermentativo, favorecendo o maior desempenho do animal (Muck, 1993).

Objetivou-se com este trabalho avaliar a composição bromatológica e a digestibilidade in vitro da matéria seca de silagens de milho e de sorgo tratadas com inoculantes microbianos.

\section{Material e Métodos}

O experimento foi conduzido no período de outubro de 1998 a abril de 1999 nas dependências do Departamento de Zootecnia (DZO) da Universidade Federal de Viçosa (UFV), na cidade de Viçosa, Minas Gerais, situada a $20^{\circ}$ e $45^{\prime}$ de latitude sul, $42^{\circ}$ e $51^{\prime}$ de longitude oeste e $657 \mathrm{~m}$ de altitude, apresentando pre- cipitação média anual de $1.341 \mathrm{~mm}$, dos quais aproximadamente $86 \%$ ocorrem nos meses de outubro a março. A temperatura média das máximas é de $26,1^{\circ} \mathrm{C}$ e a média das mínimas é de $14,0^{\circ} \mathrm{C}$ (Ministério da Agricultura, 1961). O clima da região é classificado com "Cwa", segundo a classificação proposta por Köepen (1948).

Utilizou-se um arranjo fatorial $6 \times 2 \times 3$ (seis períodos de fermentação $\mathrm{x}$ duas silagens $\mathrm{x}$ três inoculantes), em delineamento inteiramente casualizado, com três repetições, para avaliação dos teores de matéria seca e proteína bruta. Para avaliação dos constituintes fibrosos e da DIVMS, consideraram-se apenas quatro períodos de fermentação (1, 14, 28 e 56 dias).

A semeadura do milho (AG 1051) e do sorgo (AG 2002) foi efetuada em outubro de 1998 , em área do Departamento de Zootecnia, respeitando-se as recomendações do produtor de sementes. Foram aplicados 300 kg/ha de 8-28-16 (N-P-K) como adubação de plantio, efetuando-se ainda duas adubações de cobertura, aos 25 e 45 dias após a semeadura, aplicando-se, respectivamente, $150 \mathrm{~kg} / \mathrm{ha}$ da mistura 20-0-20 e $100 \mathrm{~kg}$ de uréia. As plantas foram colhidas quando os grãos atingiram o estádio farináceo-duro, aos 110 e 118 dias após a semeadura, para milho e sorgo, respectivamente. A colheita foi manual e as plantas foram picadas em uma ensiladeira estacionária, previamente regulada para tamanho de partícula igual a 2,0 $\mathrm{cm}$. Foram utilizados silos experimentais de PVC dotados de válvula de Bunsen, possuidores de $40 \mathrm{~cm}$ de altura e diâmetro de $100 \mathrm{~mm}$, com capacidade aproximada de $2 \mathrm{~kg}$ de silagem. Avaliaram-se dois inoculantes microbianos comerciais: SILOBAC, da Christian Hansen (Inoculante 1), contendo Lactobacillus plantarum, Lactobacillus sp., Enterococcus faecium, Enterococcus sp., Pediococcus sp. $\left(5,26 \times 10^{10} \mathrm{ufc} / \mathrm{g}\right)$; e MAIZE-ALL, da Alltech do Brasil (Inocultante 2), contendo Enterococcus faecium (10 bilhões de ufc/g), Lactobacillus plantarum (10 bilhões de ufc/g), Pediococcus acidilactici (1 bilhão de ufc/g) e enzimas amilolíticas $(1,5 \%)$, celulolíticas $(1,5 \%)$ e proteolíticas $(2,0 \%)$. Os inoculantes foram adicionados ao material picado com auxílio de pulverizador com capacidade para $2 \mathrm{~L}$, respeitando-se as recomendações dos fabricantes. Ao material não tratado, adicionou-se quantidade de água equivalente àquela utilizada na diluição dos inoculantes. 
Amostras dos materiais frescos, antes da ensilagem e nos diferentes períodos de abertura dos silos, sofreram pré-secagem por 72 horas em estufa de ventilação forçada a $60-65^{\circ} \mathrm{C}$ e foram processadas em moinho tipo "Thomas-Willey", utilizando-se peneira de $1 \mathrm{~mm}$, sendo, em seguida, acondicionadas em frascos de vidro com tampa, para a realização das análises bromatológicas. Nessas amostras, determinaram-se os teores de matéria seca em estufa a $105^{\circ} \mathrm{C}$ e os teores de proteína bruta (PB), fibra em detergente neutro (FDN), fibra em detergente ácido (FDA), hemicelulose (HEM), celulose (CEL), lignina (LIG) e a digestibilidade in vitro da matéria seca (DIVMS), segundo recomendações de Silva (1998).

Os dados obtidos foram submetidos às análises de variância e regressão, utilizando-se o programa SAEG, versão 8.0 (Universidade Federal de Viçosa, 2000). Para os fatores qualitativos, aplicou-se o teste SNK a $5 \%$ de probabilidade na comparação das médias. A escolha das equações de regressão baseou-se no coeficiente de determinação e na significância dos coeficientes de regressão utilizando-se o teste t.

\section{Resultados e Discussão}

Na Tabela 1, encontram-se os dados referentes aos teores médios de matéria seca (MS), proteína bruta (PB), fibra em detergente neutro (FDN) e fibra em detergente ácido (FDA), celulose (CEL), hemicelulose (HEM) e lignina (LIG), determinados nas plantas de milho e sorgo antes da ensilagem.

Os teores de MS de ambas as espécies foram acima dos $25 \%$ preconizados por McDonald et al. (1991) como condição necessária para que as perdas de efluentes dentro do silo sejam minimizadas e, conseqüentemente, ocorra a manutenção dos nutrientes do material ensilado. O teor de $\mathrm{PB}$ no milho foi superior ao observado no sorgo.

Observou-se efeito $(\mathrm{P}<0,01)$ da interação período $\times$ inoculante $\times$ silagem sobre o teor de matéria seca das silagens de milho e sorgo, cujos valores médios encontram-se na Tabela 2. Analisando-se o efeito de silagem, dentro de inoculante, observa-se, na silagem de milho, que seu teor de matéria seca foi influenciado apenas no 10 e no $28^{\circ}$ dias de abertura dos silos, registrando-se menores valores no material não-tratado. Na silagem de sorgo, no entanto, não se observou efeito de inoculantes apenas aos 3 e 7 dias após a ensilagem.

Analisando-se o efeito de inoculante dentro de silagem, observou-se maiores teores de matéria seca na silagem de milho, independentemente do inoculante utilizado. Isso se explica pelo maior teor de matéria seca original na planta de milho, acrescentando-se, ainda, o caráter suculento do colmo do híbrido de sorgo AG 2002.

$\mathrm{Na}$ Figura 1 encontram-se as estimativas dos teores de matéria seca das silagens de milho e sorgo em função do período de fermentação e da adição dos diferentes inoculantes. Nas silagens de milho, estimaram-se reduções nos teores de matéria seca de 0,$0130203 ; 0,0150251$ e 0,0167204 unidades/dia de armazenamento, na silagem controle e nas silagens tratadas com Silobac e Maize-All, respectivamente (Figura 1a). Os teores de matéria seca das silagens de sorgo decresceram 0,0469853 e 0,0285382 unidades, para cada dia de fermentação, nas silagens tratadas com Silobac e Maize-All, respectivamente (Figura 1b).

$\mathrm{Na}$ Tabela 3 encontram-se os teores médios de proteína bruta das silagens, em função dos inoculantes microbianos utilizados, conforme os períodos de fermentação. Detectou-se efeito da interação período $x$ inoculante, registrando-se efeito de inoculante $(\mathrm{P}<0,05)$ somente no $28^{\circ}$ e $56^{\circ}$ o dias de fermentação. Os teores de PB das silagens de milho e sorgo deste estudo foram semelhantes àqueles observados por Pimentel et al. (1998) e Moreira et al. (2001).

Na Figura 2 encontra-se a estimativa dos teores médios de PB das silagens, em função do período de fermentação. $\mathrm{O}$ teor de $\mathrm{PB}$ da silagem não tratada não foi influenciado pelo período, registrando-se valor

Tabela 1 - Composição bromatológica das plantas de milho e sorgo antes da ensilagem

Table 1 - Chemical composition of sorghum and corn plants before the fermentation

\begin{tabular}{|c|c|c|c|c|c|c|c|}
\hline \multirow{2}{*}{$\begin{array}{l}\text { Planta } \\
\text { Forage specie }\end{array}$} & \multirow[t]{2}{*}{$\operatorname{MS}(\%)$} & $\mathrm{PB}(C P)$ & $\mathrm{FDN}(N D F)$ & $\operatorname{FDA}(A D F)$ & CEL (CEL) & $\operatorname{HEM}(C E L)$ & $\operatorname{LIG}(L I G)$ \\
\hline & & \multicolumn{6}{|c|}{ Expresso na MS (Expressed in DM) } \\
\hline Corn & & & & & & & \\
\hline Sorgo & 25,38 & 6,22 & 62,65 & 31,38 & 23,59 & 28,56 & 4,77 \\
\hline Sorghum & & & & & & & \\
\hline
\end{tabular}


Tabela 2 - Teores médios de matéria seca de silagens de milho e de sorgo, tratadas ou não com inoculantes microbianos, nos diferentes períodos fermentação

Table 2 - Average contents of dry matter (DM) of corn and sorghum silage with or without microbial inoculants in several fermentation periods

\begin{tabular}{|c|c|c|}
\hline \multirow[b]{2}{*}{$\begin{array}{l}\text { Inoculante } \\
\text { Inoculant }\end{array}$} & \multicolumn{2}{|c|}{$\begin{array}{l}\text { Silagem } \\
\text { Silage }\end{array}$} \\
\hline & $\begin{array}{l}\text { Milho } \\
\text { Corn }\end{array}$ & $\begin{array}{c}\text { Sorgo } \\
\text { Sorghum }\end{array}$ \\
\hline & \multicolumn{2}{|c|}{$\begin{array}{l}1 \text { dia de ensilagem } \\
1 \text { day of ensilage }\end{array}$} \\
\hline $\begin{array}{l}\text { Controle (Control) } \\
\text { Silobac } \\
\text { Maize-All }\end{array}$ & $\begin{array}{l}30,24 \mathrm{Ba} \\
31,04 \mathrm{Aa} \\
31,45 \mathrm{Aa}\end{array}$ & $\begin{array}{l}25,72 \mathrm{Ab} \\
24,83 \mathrm{Bb} \\
24,90 \mathrm{Bb}\end{array}$ \\
\hline Maize-All & \multicolumn{2}{|c|}{$\begin{array}{l}3 \text { dias de ensilagem } \\
3 \text { days of ensilage }\end{array}$} \\
\hline $\begin{array}{l}\text { Controle (Control) } \\
\text { Silobac } \\
\text { Maize-All }\end{array}$ & $\begin{array}{l}29,74 \mathrm{Aa} \\
30,16 \mathrm{Aa} \\
30,20 \mathrm{Aa}\end{array}$ & $\begin{array}{l}25,79 \mathrm{Ab} \\
26,12 \mathrm{Ab} \\
25,79 \mathrm{Ab}\end{array}$ \\
\hline Maize-All & \multicolumn{2}{|c|}{$\begin{array}{l}7 \text { dias de ensilagem } \\
7 \text { days of ensilage }\end{array}$} \\
\hline $\begin{array}{l}\text { Controle (Control) } \\
\text { Silobac } \\
\text { Maize-All }\end{array}$ & $\begin{array}{l}30,19 \mathrm{Aa} \\
30,22 \mathrm{Aa} \\
30,13 \mathrm{Aa}\end{array}$ & $\begin{array}{l}25,44 \mathrm{Ab} \\
25,75 \mathrm{Ab} \\
26,31 \mathrm{Ab}\end{array}$ \\
\hline Maize-All & \multicolumn{2}{|c|}{$\begin{array}{l}14 \text { dias de ensilagem } \\
14 \text { days of ensilage }\end{array}$} \\
\hline $\begin{array}{l}\text { Controle (Control) } \\
\text { Silobac } \\
\text { Maize-All }\end{array}$ & $\begin{array}{l}30,09 \mathrm{Aa} \\
30,20 \mathrm{Aa} \\
30,59 \mathrm{Aa}\end{array}$ & $\begin{array}{l}26,76 \mathrm{Ab} \\
24,53 \mathrm{Cb} \\
25,33 \mathrm{Bb}\end{array}$ \\
\hline Maize-All & \multicolumn{2}{|c|}{$\begin{array}{l}28 \text { dias de ensilagem } \\
28 \text { days of ensilage }\end{array}$} \\
\hline $\begin{array}{l}\text { Control (Control) } \\
\text { Silobac } \\
\text { Maize-All }\end{array}$ & $\begin{array}{l}29,68 \mathrm{Ba} \\
30,50 \mathrm{Aa} \\
30,91 \mathrm{Aa}\end{array}$ & $\begin{array}{l}26,58 \mathrm{Ab} \\
23,83 \mathrm{Bb} \\
24,23 \mathrm{Bb}\end{array}$ \\
\hline Maize-All & \multicolumn{2}{|c|}{$\begin{array}{l}56 \text { dias de ensilagem } \\
56 \text { days of ensilage }\end{array}$} \\
\hline $\begin{array}{l}\text { Controle (Control) } \\
\text { Silobac } \\
\text { Maize-All }\end{array}$ & $\begin{array}{l}29,40 \mathrm{Aa} \\
29,62 \mathrm{Aa} \\
29,63 \mathrm{Aa}\end{array}$ & $\begin{array}{l}26,52 \mathrm{Ab} \\
23,45 \mathrm{Cb} \\
24,37 \mathrm{Bb}\end{array}$ \\
\hline
\end{tabular}

Médias seguidas por letras maiúsculas iguais nas colunas e por letras minúsculas iguais nas linhas, em cada período, não diferem significativamente a $5 \%$ de probabilidade pelo teste SNK.

Means followed by equal capital letter in the column and small letters in a row, in each period, do not differ at $5 \%$ of probability by SNK test.

médio de $6,9 \%$, enquanto, nas silagens tratadas com Silobac e Maize-All, detectaram-se efeitos linear e quadrático, respectivamente. No primeiro caso, estimou-se incremento de 0,00774033 unidades no teor protéico para cada dia de fermentação. Todavia, na silagem tratada com Maize-All, estimou-se valor
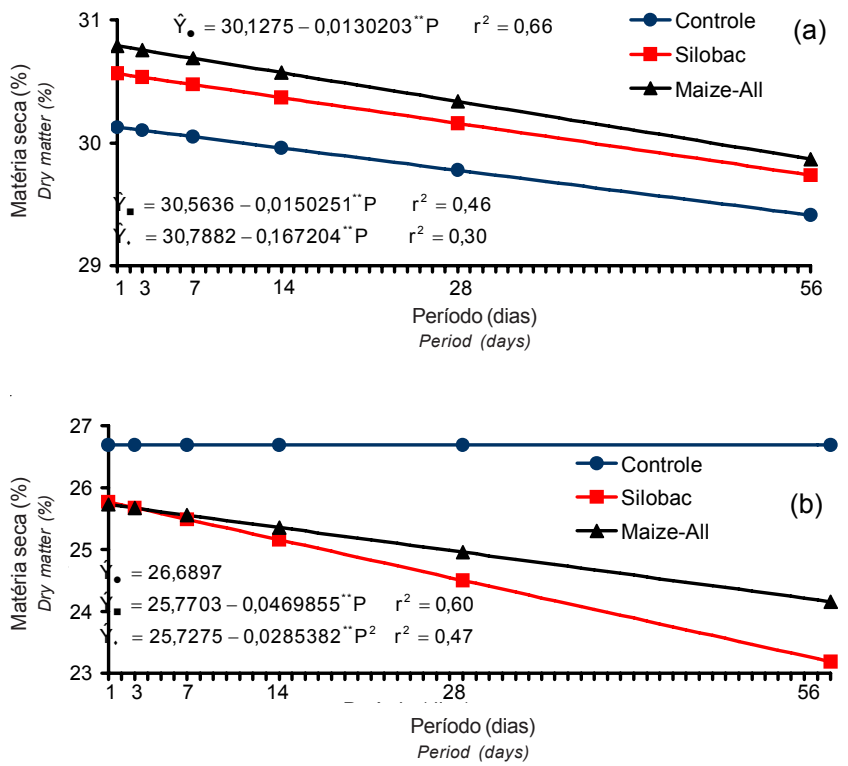

** Significativo a $1 \%$ de probabilidade pelo teste $\mathrm{t}$.

** Significant at $1 \%$ of probability by Student test.

Figura 1 - Estimativa dos teores médios de matéria seca das silagens de milho (a) e de sorgo (b) em função dos períodos de fermentação $(P)$ e dos respectivos inoculantes.

Figure 1 - Estimate of average dry matter content of corn (a) and sorghum (b) silages, as affected by the fermentation periods $(P)$ and the respective inoculants.

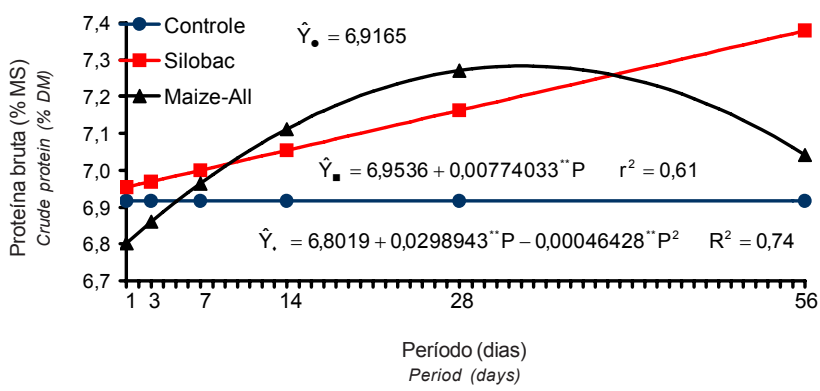

** Significativo a $1 \%$ de probabilidade pelo teste $t$.

** Significant at $1 \%$ of probability by Student test.

Figura 2 - Estimativa dos teores médios de proteína bruta das silagens em função dos períodos de fermentação (P) e dos respectivos inoculantes.

Figure 2 - Estimates of average crude protein contents of silages, as affected by the fermentation periods $(P)$ and the respective inoculant. 
Tabela 3 - Teores médios de proteína bruta (\% MS), em função de inoculantes microbianos e períodos de fermentação Table 3 - Average contents of crude protein (DM, \%) as affected by the microbial inoculants and the fermentation periods

\begin{tabular}{lcccccc}
\hline & \multicolumn{5}{c}{$\begin{array}{c}\text { Período de fermentação (dias) } \\
\text { Fermentation period (days) }\end{array}$} \\
\cline { 2 - 7 } $\begin{array}{l}\text { Inoculante } \\
\text { Inoculant }\end{array}$ & 1 & 3 & 7 & 14 & 28 & 56 \\
\hline Controle & $6,73 \mathrm{~A}$ & $6,94 \mathrm{~A}$ & $7,13 \mathrm{~A}$ & $6,95 \mathrm{~A}$ & $6,77 \mathrm{C}$ & $6,97 \mathrm{~B}$ \\
$\begin{array}{l}\text { Control } \\
\text { Silobac }\end{array}$ & $6,87 \mathrm{~A}$ & $6,91 \mathrm{~A}$ & $7,20 \mathrm{~A}$ & $7,15 \mathrm{~A}$ & $7,00 \mathrm{~B}$ & $7,42 \mathrm{~A}$ \\
Maize-All & $6,75 \mathrm{~A}$ & $6,94 \mathrm{~A}$ & $7,12 \mathrm{~A}$ & $7,00 \mathrm{~A}$ & $7,31 \mathrm{~A}$ & $7,02 \mathrm{~B}$ \\
\hline
\end{tabular}

Letras maiúsculas distintas nas colunas diferem significativamente a $5 \%$ de probabilidade pelo teste SNK.

Means followed by equal capital letter in the column do not differ at $5 \%$ of probability by SNK test.

máximo de 7,28\% de $\mathrm{PB}$ aos 32,19 dias de fermentação, o que não tem uma explicação biológica consistente, pois esperava-se que os teores de proteína bruta permanecessem inalterados ao longo do período de fermentação. É possível que isso tenha decorrido da melhor conservação da PB das silagens tratadas, em função da redução do nitrogênio amoniacal/Ntotal nessas silagens (dados não apresentados).

A exemplo do observado em relação à matéria seca, detectou-se efeito da interação período $\times$ silagem $\times$ inoculante sobre os teores de fibra em detergente neutro e em detergente ácido. Na Tabela 4 encontram-se os teores médios de FDN das silagens de milho e sorgo em função de inoculantes microbianos e dos períodos de fermentação. Analisando-se o efeito de silagem dentro de inoculante no $28^{\circ}$ e no último dia de abertura dos silos, constataram-se menores teores de FDN nas silagens de milho tratadas com inoculantes microbianos, registrando-se menor valor naquela tratada com Maize-All. Por sua vez, entre as silagens de sorgo, registrou-se menor teor de FDN naquela não tratada. O menor teor de FDN na silagem de milho tratada com o inoculante Maize-All deve-se, provavelmente, à maior disponibilização de substratos fermentativos nesta silagem, como celulose e hemicelulose, que podem ter ocorrido por um conjunto de eventos ainda não totalmente elucidados, como o interrelacionamento entre microrganismos, enzimas e outros constituintes químicos da própria espécie vegetal, que, juntos, influenciam a velocidade da queda do $\mathrm{pH}$ e, conseqüentemente, a ação dos microrganismos e das enzimas em determinado universo fermentativo.

Os teores de FDN das silagens de milho e sorgo deste estudo encontram-se dentro da faixa normal- mente registrada em outros trabalhos, no Brasil, como aqueles observados por Silva et al. (1999), quando da avaliação de silagens destas espécies.

$\mathrm{Na}$ Figura 3 encontram-se as estimativas dos teores de fibra em detergente neutro das silagens em função do período de fermentação e dos diferentes inoculantes microbianos. Observou-se efeito quadrático de período sobre os teores de FDN das
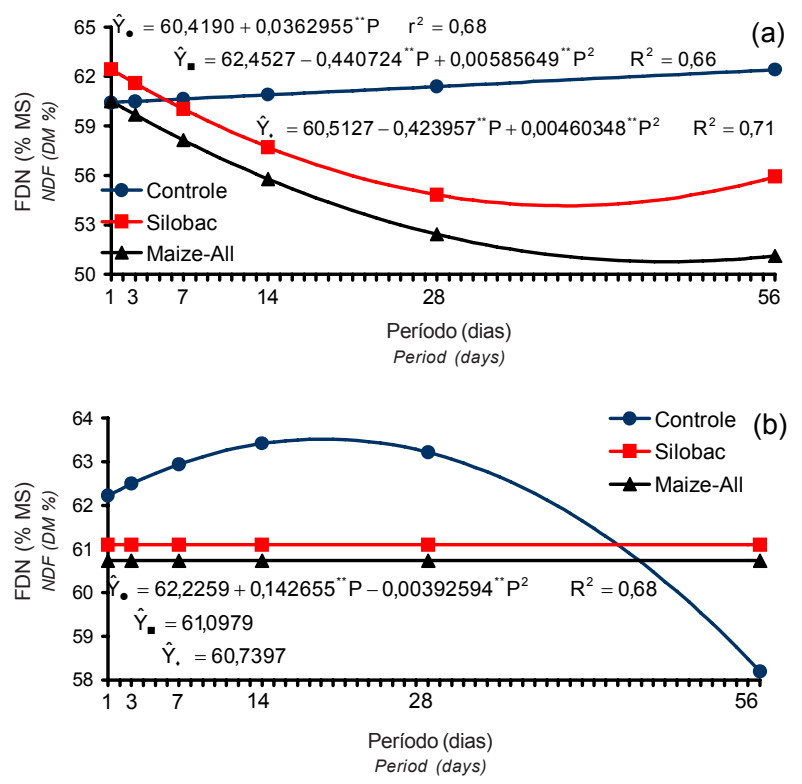

** Significativo a $1 \%$ de probabilidade, pelo teste de $\mathrm{t}$.

** Significant at $1 \%$ of probability by Student test.

Figura 3 - Estimativa dos teores médios de fibra em detergente neutro das silagens de milho (a) e sorgo (b), em função do período fermentação $(P)$, e respectivos inoculantes.

Figure 3 - Estimates of average neutral detergent fiber contents of corn (a) and sorghum (b) silages, as affected by the fermentation periods $(P)$ and the respective inoculants. 
Tabela 4 - Teores médios de fibra em detergente neutro (\% da MS) de silagens de milho e sorgo, tratadas ou não com inoculantes microbianos, nos diferentes períodos de fermentação

Table 4 - Average contents of neutral detergent fiber (DM, \%) of corn and sorghum silage with or without microbial inoculants in several fermentation periods

\begin{tabular}{|c|c|c|}
\hline \multirow[b]{2}{*}{$\begin{array}{l}\text { Inoculante } \\
\text { Inoculant }\end{array}$} & \multicolumn{2}{|c|}{$\begin{array}{l}\text { Silagem } \\
\text { Silage }\end{array}$} \\
\hline & $\begin{array}{l}\text { Milho } \\
\text { Corn }\end{array}$ & $\begin{array}{l}\text { Sorgo } \\
\text { Sorghum }\end{array}$ \\
\hline & \multicolumn{2}{|c|}{$\begin{array}{l}1 \text { dia de ensilagem } \\
1 \text { day of ensilage }\end{array}$} \\
\hline $\begin{array}{l}\text { Controle (Control) } \\
\text { Silobac } \\
\text { Maize-All }\end{array}$ & $\begin{array}{l}62,82 \mathrm{Aa} \\
61,06 \mathrm{ABa} \\
59,15 \mathrm{Ba}\end{array}$ & $\begin{array}{l}63,06 \mathrm{Aa} \\
61,22 \mathrm{Aa} \\
61,75 \mathrm{Aa}\end{array}$ \\
\hline Maize-All & \multicolumn{2}{|c|}{$\begin{array}{l}14 \text { dias de ensilagem } \\
14 \text { days of ensilage }\end{array}$} \\
\hline $\begin{array}{l}\text { Controle (Control) } \\
\text { Silobac } \\
\text { Maize-All }\end{array}$ & $\begin{array}{l}59,76 \mathrm{Aa} \\
59,85 \mathrm{Aa} \\
57,87 \mathrm{Aa}\end{array}$ & $\begin{array}{l}61,69 \mathrm{Aa} \\
63,60 \mathrm{Aa} \\
62,61 \mathrm{Aa}\end{array}$ \\
\hline Maize-All & \multicolumn{2}{|c|}{$\begin{array}{l}28 \text { dias de ensilagem } \\
28 \text { days of ensilage }\end{array}$} \\
\hline $\begin{array}{l}\text { Controle (Control) } \\
\text { Silobac } \\
\text { Maize-All }\end{array}$ & $\begin{array}{l}58,55 \mathrm{Ab} \\
52,96 \mathrm{Ba} \\
50,52 \mathrm{Ca}\end{array}$ & $\begin{array}{l}64,42 \mathrm{Aa} \\
58,63 \mathrm{Ba} \\
59,31 \mathrm{Ba}\end{array}$ \\
\hline Maize-All & \multicolumn{2}{|c|}{$\begin{array}{l}56 \text { dias de ensilagem } \\
56 \text { days of ensilage }\end{array}$} \\
\hline $\begin{array}{l}\text { Controle (Control) } \\
\text { Silobac } \\
\text { Maize-All }\end{array}$ & $\begin{array}{l}64,14 \mathrm{Aa} \\
56,42 \mathrm{Ba} \\
51,49 \mathrm{Ca}\end{array}$ & $\begin{array}{l}57,69 \mathrm{Ba} \\
60,94 \mathrm{Aa} \\
59,28 \mathrm{Aba}\end{array}$ \\
\hline
\end{tabular}

Médias seguidas por letras maiúsculas iguais nas colunas e por letras minúsculas iguais nas linhas, para cada período, não diferem significativamente a $5 \%$ de probabilidade pelo teste SNK. Means followed by equal capital letter in the column and small letters in a row, for each period, do not differ at $5 \%$ of probability by SNK test).

silagens de milho tratadas com os inoculantes Silobac e Maize-All, obtendo-se valores mínimos, respectivamente, de 51,08 e 50,75\%, aos 37,63 e 46,05 dias após a ensilagem (Figura 3a). Na silagem de milho não tratada, houve pequenos acréscimos na FDN de 0,0362955 unidades por dia de fermentação. No caso das silagens tratadas, isso pode ser explicado pelo efeito de diluição, decorrente do aumento no teor protéico das silagens, com o período de fermentação, ou ainda, da hidrólise ácida da FDN, pela maior disponibilidade de substratos passíveis de serem solubilizados. No entanto, novas pesquisas são necessárias, a fim de se caracterizar a veracidade desta hipótese. Entre as silagens de sorgo, observou-se efeito apenas naquela não tratada, estimando-se valor máximo de $63,52 \%$ aos 18,17 dias (Figura 3b), indicando que nem sempre a adição de aditivos contendo microrganismos é eficiente na disponibilização de constituintes da fração fibrosa, que são passíveis de serem hidrolizados. Alguns pesquisadores, como Phillip \& Fellner (1992) e Kung Jr. \& Ranjit (2001), constataram que silagens de milho tratadas com inoculantes microbianos contendo ou não enzimas não apresentaram respostas positivas quanto à redução da fração de FDN. Esta variação de resposta ainda não foi totalmente elucidada, sobretudo na avaliação do efeito da adição de enzimas (celulolíticas, hemicelulolíticas e amilolíticas) via inoculantes microbianos (Woolford, 1984; Meeske, 2001), o que justifica futuras ações de pesquisadores que atuam na área de conservação de plantas forrageiras, buscando elucidar as relações entre as diferentes espécies de plantas, espécies e cepas de bactérias e enzimas antes de se predizer as possíveis respostas pelos ruminantes (Phillip \& Fellner, 1992).

Os teores médios de FDA das silagens de milho e sorgo, tratadas ou não com inoculantes microbianos, em função do período de fermentação, são apresentados na Tabela 5. Analisando o efeito de inoculante dentro de silagens, constatou-se que os teores de FDA foram semelhantes $(\mathrm{P}>0,05)$ entre as silagens de milho e sorgo, independentemente do inoculante utilizado. Quanto ao efeito de silagem dentro de inoculante, no último dia de abertura dos silos, verificou-se, entre as silagens de milho, menores teores de FDA naquelas tratadas com inoculantes microbianos, que, por sua vez, não diferiram $(\mathrm{P}>0,05)$ entre si. Entre as silagens de sorgo, registrou-se menor valor na silagem controle, como constatado para o teor de FDN.

Ranjit \& Kung Jr. (2000) também observaram redução dos teores de FDA na silagem de milho tratada com L. plantarum após 100 dias de ensilagem. No entanto, não foram observadas reduções quando outros microrganismos foram testados.

$\mathrm{Na}$ Figura 4 encontra-se a estimativa dos teores de fibra em detergente ácido das silagens em função do período fermentação e dos diferentes inoculantes microbianos utilizados. Na silagem de milho, observou-se efeito somente na ausência do inoculante microbiano, estimando-se valor mínimo de 30,27\% aos 25,35 dias após a ensilagem (Figura 4a). Quanto às silagens de sorgo, observou-se efeito quadrático $(\mathrm{P}<0,01)$ no teor de FDA da silagem tratada com 
inoculante Maize-All, estimando-se valor máximo de $35,69 \%$ aos 26,39 dias após a ensilagem. Os teores de FDA da silagem de sorgo não tratada e daquela tratada com o inoculante Silobac não foram influenciados pelo período de fermentação, apresentando, respectivamente, valores médios de 33,12 e $34,20 \%$ de FDA (Figura 4b).

Quanto à celulose, detectou-se efeito apenas da interação silagem $\times$ inoculante (Tabela 6). Entre as silagens de milho, registrou-se menor teor de celulose nas tratadas, que, por sua vez, não diferiram entre si $(\mathrm{P}>0,05)$. Por outro lado, os teores de celulose na silagem de sorgo não foram influenciados pelo uso de inoculantes. Esse aumento de solubilização da celulose notado nas silagens de milho contribui diretamente para a maior preservação de seus nutrientes e pode provavelmente influenciar a produção de ácidos orgânicos de suas silagens. Esse resultado indica que a utilização de inoculantes microbianos nas silagens ricas em grãos e que possuem altos teores de carboidratos solúveis é justificável, por assegurar a maior preservação do material ensilado por meio da

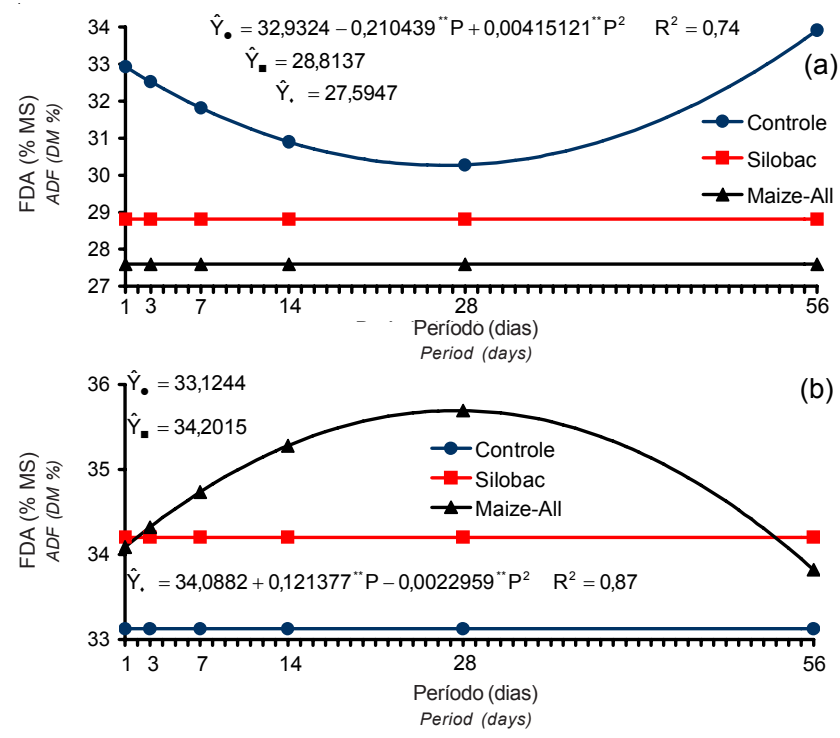

** Significativo a $1 \%$ de probabilidade pelo teste $\mathrm{t}$.

** Significant at $1 \%$ of probability by Student test.

Figura 4 - Estimativa dos teores médios de fibra em detergente ácido das silagens de milho (a) e de sorgo (b), em função dos períodos de fermentação $(P)$ e dos respectivos inoculantes.

Figure 4 - Estimate of average acid detergent fiber contents of corn (a) and sorghum (b) silages as affected by the fermentation periods $(P)$ and the respective inoculants. solubilização tardia de alguns substratos, que estão diretamente relacionados à manutenção das condições ótimas (baixo $\mathrm{pH}$, por exemplo) e dos microrganismos desejáveis (Kung Jr., 2001). Porém, Ferlon et al. (1995) alertam que a maior disponibilização de açúcares para o processo fermentativo de silagens ricas em grãos nem sempre é positiva, uma vez que há possibilidade de esses açúcares também favorecerem a produção de alcoóis por leveduras, o que representa aumento de perda da matéria seca e da capacidade de putrefação da silagem após a abertura do silo e redução do consumo de silagem pelo animal.

Observou-se efeito $(\mathrm{P}<0,05)$ dos fatores silagem, inoculante e período sobre os teores de hemicelulose das silagens. A silagem de milho apresentou valor superior àquele observado na silagem de sorgo $(29,8 \times 28,4 \%)$.

Na Tabela 7 encontram-se os teores médios de hemicelulose das silagens em função dos inoculantes. Observou-se menor valor nas silagens tratadas com inoculante microbiano Maize-All, que não diferiu $(\mathrm{P}>0,05)$ da silagem tratada com Silobac, que foi semelhante à silagem não tratada.

Segundo Muck \& Kung Jr. (1997), a redução dos teores de hemicelulose das silagens deve-se à presença de hemicelulases na planta ensilada, porém, a efetividade destas enzimas varia significativamente conforme a fonte e os subtratos relacionados. De acordo com O'Kiely \& Flynn (1985), a inclusão de enzimas na confecção de inoculantes microbianos

Tabela 6 - Teores médios de celulose (\% MS) das silagens de milho e de sorgo, em função dos inoculantes microbianos

Table 6 - Average contents of cellulose (DM, \%) of corn and sorghum silage as affected by the microbial inoculants

\begin{tabular}{lccc}
\hline & \multicolumn{3}{c}{$\begin{array}{c}\text { Inoculante } \\
\text { Inoculant }\end{array}$} \\
\cline { 2 - 4 } $\begin{array}{l}\text { Silagem } \\
\text { Silage }\end{array}$ & $\begin{array}{c}\text { Controle } \\
\text { Control }\end{array}$ & Silobac & Maize-All \\
\hline $\begin{array}{l}\text { Milho } \\
\text { Corn }\end{array}$ & $27,45 \mathrm{Aa}$ & $24,51 \mathrm{Bb}$ & $23,80 \mathrm{Bb}$ \\
$\begin{array}{l}\text { Sorgo } \\
\text { Sorghum }\end{array}$ & $27,35 \mathrm{Aa}$ & $28,70 \mathrm{Aa}$ & $29,28 \mathrm{Aa}$ \\
\hline
\end{tabular}

Médias seguidas por letras maiúsculas iguais na mesma coluna e minúsculas na linha não diferem significativamente a $5 \%$ de probabilidade pelo teste SNK.

Means followed by equal capital letter in the column and small letters in a row do not differ at $5 \%$ of probability by SNK test. 
Tabela 7 - Teores médios de hemicelulose (\% MS) das silagens, em função dos inoculantes microbianos

Table 7 - Average contents of hemicelullose (DM, \%) of corn and sorghum silage as affected by the microbial inoculants

\begin{tabular}{lc}
\hline $\begin{array}{l}\text { Inoculante } \\
\text { Inoculant }\end{array}$ & $\begin{array}{c}\text { Hemicelulose } \\
\text { Hemicelullose }\end{array}$ \\
\hline Controle & $30,20 \mathrm{~A}$ \\
Control & $29,13 \mathrm{AB}$ \\
Silobac & $27,95 \mathrm{~B}$ \\
\hline Maize-All & \\
\hline
\end{tabular}

Médias seguidas por letras maiúsculas iguais na mesma coluna e minúsculas na linha não diferem significativamente a $5 \%$ de probabilidade pelo teste SNK.

Means followed by equal capital letter in the column and small letters in a row do not differ at $5 \%$ of probability by SNK test.

pode ser eficiente na quebra de constituintes que compõem os carboidratos estruturais das células vegetais e, desta forma, fornecer açúcares adicionais como substrato para os microrganismos. Porém, Muck (1996) enfatizou a necessidade de manutenção das silagens sob baixos valores de $\mathrm{pH}$ para que a hemicelulose possa ser quebrada pelas enzimas, sendo este efeito geralmente pequeno. Conforme Nadeu et al. (2000), o sucesso do emprego de inoculantes microbianos contendo enzimas que potencialmente solubilizam as frações da parede celular tem sido inconsistente, sobretudo pela carência de informações que relacionem o efeito direto dessas enzimas sobre cada espécie forrageira utilizada na ensilagem, pela falta de pesquisas que indiquem as doses ideais de aplicação desses produtos e pela pequena quantidade de dados até hoje obtidos que expliquem nitidamente o efeito dessas enzimas sobre a fermentação de silagens.

$\mathrm{Na}$ Figura 5, encontra-se a estimativa dos teores de hemicelulose das silagens em função dos períodos de fermentação. Observou-se efeito quadrático $(\mathrm{P}<0,01)$, estimando-se valor mínimo de 28,27\% aos 41,42 dias.

Quanto aos teores de lignina, observou-se efeito das interações silagem $x$ período $(\mathrm{P}<0,05)$ e período $\mathrm{x}$ inoculante $(\mathrm{P}<0,01)$. Na Tabela 8 , encontram-se os teores médios de lignina nas silagens de milho e de sorgo em função do período de fermentação. Essa fração não diferiu $(\mathrm{P}>0,05)$ entre as silagens em todos os períodos avaliados. Avaliando-se o efeito de inoculante, dentro de período, também não se detectou efeito de período sobre os teores de lignina, estimando-se valores médios de 4,29; 4,16 e 3,93\%, respectivamente, nas silagens controle e tratadas com Silobac

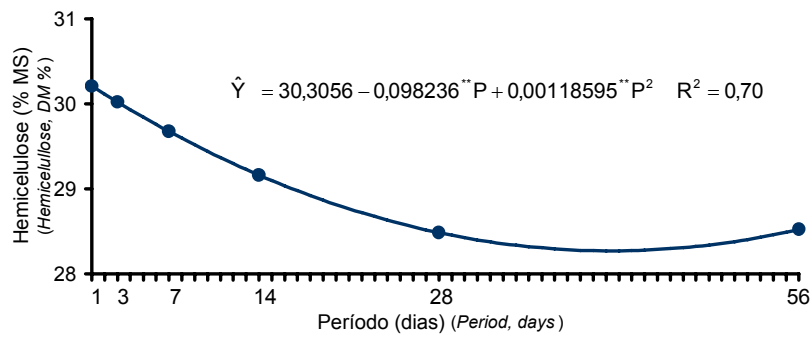

** Significativo a $1 \%$ de probabilidade pelo teste $\mathrm{t}$.

** Significant at $1 \%$ of probability by Student test.

Figura 5 - Estimativa dos teores médios de hemicelulose (\% da MS) das silagens, em função dos períodos de fermentação $(P)$.

Figure 5 - Estimate of average hemicelullose contents (DM, $\%)$ of silages as affected by the fermentation periods $(P)$.

e Maize-All. Também não se detectou efeito de período sobre os teores de lignina de silagens de milho e sorgo (médias de 4,24 e 4,01\%, respectivamente), o que já era esperado, uma vez que esta fração mantém-se inalterada ao longo do processo fermentativo (Van Soest, 1994).

Nos dados de digestibilidade in vitro da matéria seca (DIVMS), detectou-se efeito $(\mathrm{P}<0,05)$ da interação silagem $\times$ inoculante $\times$ período. $\mathrm{Na}$ Tabela 9 são apresentados os valores médios de DIVMS das silagens de milho e sorgo, tratadas ou não com inoculantes microbianos, em função dos período de fermentação. Observou-se menor $(\mathrm{P}<0,05)$ valor de DIVMS na silagem de milho não tratada com inoculante microbiano a partir dos 14 dias de abertura dos silos. Na DIVMS das silagens de sorgo, não se detectou efeito dos inoculantes em nenhum dos períodos de fermentação.

Observou-se efeito quadrático $(\mathrm{P}<0,05)$ dos períodos sobre a DIVMS das silagens de milho tratadas com os inoculantes Silobac e Maize-All, estimandose, respectivamente, valores máximos de 71,16 e $71,66 \%$ aos 48,40 e 50,28 dias. Dados sumarizados por Muck \& Kung Jr. (1997) envolvendo estudos de silagens tratadas com inoculantes microbianos indicaram que a inoculação melhorou a digestibilidade da matéria seca das silagens em aproximadamente $30 \%$, em um total de 82 estudos avaliados. De acordo com Muck (1993), as causas desse efeito não são completamente claras, uma vez que as bactérias ácidoláticas não degradam componentes da parede celular ou qualquer outro componente que limite a digestibilidade. Segundo esse autor, o menor $\mathrm{pH}$ de silagens inoculadas pode promover a hidrólise ácida 
Tabela 8 - Teores médios de lignina (\% da MS) das silagens de milho e sorgo em função do período de fermentação

Table 8 - Average contents of lignin (DM, \%) of corn and sorghum silage as affected by the fermentation periods

\begin{tabular}{lcccc}
\hline & \multicolumn{4}{c}{$\begin{array}{c}\text { Período de fermentação (dias) } \\
\text { Fermentation }\end{array}$} \\
\cline { 2 - 5 } $\begin{array}{l}\text { Silageriod (days) } \\
\text { Silage }\end{array}$ & 1 & 14 & 28 & 56 \\
\hline $\begin{array}{l}\text { Milho } \\
\text { Corn }\end{array}$ & $4,69 \mathrm{~A}$ & $4,51 \mathrm{~A}$ & $3,95 \mathrm{~A}$ & $4,40 \mathrm{~A}$ \\
$\begin{array}{l}\text { Sorgo } \\
\text { Sorghum }\end{array}$ & 3,90 A & $3,82 \mathrm{~A}$ & $3,55 \mathrm{~A}$ & $3,91 \mathrm{~A}$ \\
\hline
\end{tabular}

Médias seguidas por letras maiúsculas iguais na mesma coluna e minúsculas na linha não diferem significativamente a $5 \%$ de probabilidade pelo teste SNK.

Means followed by equal capital letter in the column and small letters in a row do not differ at $5 \%$ of probability by SNK test.

Tabela - Valores de digestilidade in vitro da matéria seca de silagens de milho e de sorgo, tratadas ou não com inoculantes microbianos, em função do período de fermentação

Table 9 - Average contents of "in vitro" dry matter digestibility of corn and sorghum silage with or without microbial inoculants as affected by the fermentation periods

\begin{tabular}{lcc}
\hline & \multicolumn{2}{c}{$\begin{array}{c}\text { Silagem } \\
\text { Silage }\end{array}$} \\
\cline { 2 - 3 } Inoculante & Milho & Sorgo \\
Inoculant & Corn & Sorghum \\
\hline
\end{tabular}

1 dia de ensilagem

1 day of ensilage

Controle (Control)

Silobac

Maize-All

$$
\begin{array}{ll}
66,89 \mathrm{Aa} & 58,31 \mathrm{Aa} \\
66,43 \mathrm{Aa} & 59,60 \mathrm{Aa} \\
67,12 \mathrm{Aa} & 59,42 \mathrm{Aa}
\end{array}
$$

14 dias de ensilagem

14 days of ensilage

$\begin{array}{lll}\text { Controle (Control) } & 66,60 \mathrm{Ba} & 59,44 \mathrm{Aa} \\ \text { Silobac } & 69,47 \mathrm{Aa} & 59,16 \mathrm{Aa} \\ \text { Maize-All } & 68,89 \mathrm{Aa} & 59,37 \mathrm{Aa}\end{array}$

28 dias de ensilagem

28 days of ensilage

\begin{tabular}{lcc} 
Controle (Control) & $67,95 \mathrm{Ba}$ & $60,85 \mathrm{Aa}$ \\
Silobac & $69,85 \mathrm{Aa}$ & $61,03 \mathrm{Aa}$ \\
Maize-All & $70,90 \mathrm{Aa}$ & $61,28 \mathrm{Aa}$ \\
& \multicolumn{2}{c}{56 dias de ensilagem } \\
& \multicolumn{2}{c}{56 days of ensilage } \\
Controle(Control) & $68,28 \mathrm{Ba}$ & $60,01 \mathrm{Aa}$ \\
Silobac & $71,12 \mathrm{Aa}$ & $60,89 \mathrm{Aa}$ \\
Maize-All & $71,57 \mathrm{Aa}$ & $60,63 \mathrm{Aa}$
\end{tabular}

Médias seguidas por letras maiúsculas iguais na mesma coluna e minúsculas na linha não diferem significativamente a $5 \%$ de probabilidade pelo teste SNK.

Means followed by equal capital letter in the column and small letters in a row do not differ at $5 \%$ of probability by SNK test. da hemicelulose, resultando em ruptura das células da forragem e favorecendo um ataque mais extensivo pelos microrganismos ruminais. Contudo, deve-se salientar que, neste estudo, os inoculantes não influenciaram o $\mathrm{pH}$ das silagens, registrando-se valores médios de 3,81 e 3,62, para silagens de milho e sorgo, respectivamente. É oportuno destacar que os períodos de valores máximos de DIVMS da silagem de milho foram próximos àqueles que resultaram em mínimos teores de FDN (37,63 e 46,05 dias) dessas silagens, quando tratadas com os inoculantes Silobac e Maize-All, respectivamente. Deve-se acrescentar ainda que o inoculante Maize-All apresenta em sua constituição uma enzima que degrada a parede celular (celulase), cujo principal objetivo é reduzir o conteúdo de fibra (FDN ou FDA) na silagem, liberando açúcares adicionais que podem ser utilizados para fermentação pelas bactérias ácido-láticas. Porém, o inoculante Silobac, não possuindo esta mesma enzima, indica a ocorrência de outros eventos ainda obscuros em nível de pesquisa, oriundos do uso destes produtos microbianos, que nem sempre foram capazes de favorecer o aumento da DIVMS, dada a dependência de sua ação quanto à espécie vegetal conservada.

As DIVMS das silagens de sorgo não foram influenciadas pelos inoculantes microbianos, registrando-se valores médios de 59,7; 60,2 e 60,2\%, respectivamente, nas silagens tratadas ou não com os inoculantes Silobac e Maize-All.

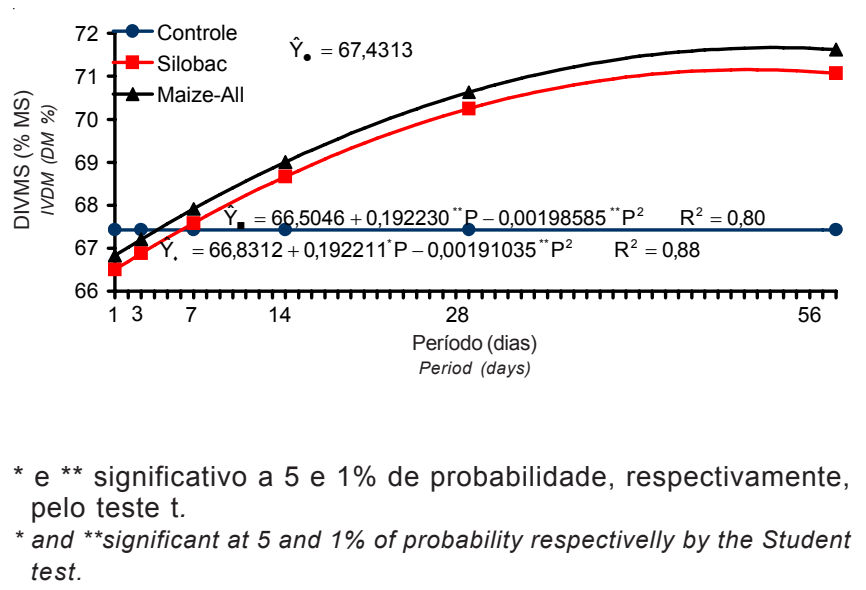

Figura 6 - Estimativa da digestibilidade in vitro da matéria seca (DIVMS) de silagens de milho, em função do período de fermentação $(P)$ e dos respectivos inoculantes.

Figure 6 - Estimated "in vitro" dry matter digestibility (IVDMD) to corn (a) and sorghum (b) silages as affected by the fermentation periods $(P)$ and the respective inoculants. 


\section{Conclusões}

Os inoculantes microbianos foram mais efetivos na silagem de milho, pois promoveram reduções nos componentes fibrosos (FDN, FDA, celulose e hemicelulose) da silagem, resultando em maior digestibilidade in vitro da matéria seca e, portanto, maior valor nutritivo potencial.

\section{Literatura Citada}

CHERNEY, J.H.; MOORE, K.J.; VOLENEC, J.J. et al. Rate and extent of digestion of cell wall components of brownmidrib sorghum species. Crop Science, v.26, n.5, p.10551059, 1986.

FERLON, D.R.; HENDERSON, A.R.; ROOKE, J.A. The fermentative preservation of grasses and forage crops. Journal of Applied Bacteriology, Suppl., v.79, n.24, p.118S-131S, 1995.

FERREIRA, J.J. Aspectos importantes para melhorar a qualidade da silagem de milho e maior eficiência na sua utilização. In: Milho para silagem: tecnologias, sistemas e custo de produção. Sete Lagoas: CNPMS/Embrapa, 1991.p.59-67. (Circular Técnica, 14)

HENDERSON, N. Silage additives. Animal Feed Science and Technology, v.45, p.35-56, 1993.

KUNG JR., L. Silage fermentation and additives. In: SCIENCE AND TEHCNOLOGY IN THE FEED INDUSTRY, 17. 2001, Nottingham. Proceedings... Nottingham: Nottingham University Press, 2001. p.145-159.

KUNG JR., L.; RANJIT, N.K. The effect of Lactobacillus buchneri and other additives on the fermentation and aerobic stability of barley silage. Journal of Dairy Science, v.84, n5, p.1149-1155, 2001.

McDOnAld, P.; HENDERSON, A.R.; HERON, S.J.E. The biochemistry of silage. 2.ed. Marlow: Chalcombe Pub, 1991. 340p.

MEESKE, R. Ensiling maize, tropical grass and big bale oat silage with inoculants in South Africa. In: SCIENCE AND TEHCNOLOGY IN THE FEED INDUSTRY, 17., 2001, Nottingham. Proceedings... Nottingham:Nottingham University Press, 2001. p.115-125.

MOREIRA, A.L.; PEREIRA, O.G.; GARCIA, R. et al. Produção de leite, consumo e digestibilidade aparente dos nutrientes, $\mathrm{pH}$ e concentração de amônia ruminal em vacas lactantes recebendo rações contendo silagem de milho e fenos de alfafa e de capim-Coastcross. Revista Brasileira de Zootecnia, v.30, n.3, p.1089-1105, 2001.

MUCK, R.E. Inoculation of silage and its effects on silage quality. In: INFORMATIONAL CONFERENCE WITH DAIRY AND FORAGE INDUSTRIES, 1996, Madison. Proceedings... Madison: USDFRC, 1996. p.43-51.

MUCK, R.E. The role of silage additives in making high quality silage. In: SILAGE PRODUCTION FROM SEED TO ANIMAL, 1993, New York. Proceedings... New York: NRAES, 1993. n.67, p.106-116.

MUCK, R.E.; KUNG JR., L. Effects of silage additives on ensiling. In: SILAGE:FIELD TO FEEDBUNK, 1997, Pennsylvania. Proceedings... New York: NRAES, 1997. n.99, p.187-199.
NADEAU, E.M.G.; BUXTON, D.R.; RUSSELL, J.R. et al. Enzyme, bacterial inoculante, and formic acid effects on silage composition of orchardgrass and alfafa. Journal of Dairy Science, v.83, n.7, p.1487-1502, 2000.

NANDRA, K.S.; GUPTA, B.K.; CHOPRA, A.K. The effect of stage of maturity on the digestion of hemicellulose of sorghum (Sorghum bicolor). Journal Science Food Agriculture, v.34, p.962-964, 1983.

O'KIELY, P.; FLYNN, V. Silage additives and preservatives. In: CATTLE PRODUCTION SEMINAR, 1985, Dublin. Proceedings... Dublin: Grange Research Center, 1985. p.101-115.

PETTIT, H.V. Forage quality and its limiting factors for meat production. In:SIMPÓSIO INTERNACIONAL DE FORRAGICUlTURA, 1994, Maringá. Anais... Maringá: Sociedade Brasileira de Zootecnia, 1994. p.99-118.

PHILLIP, L.E.; FELLNER, V. Effects of bacterial inoculation of high-moisture ear corn on its aerobic stability, digestion, and utilization for growth by beef steers. Journal of Animal Science, v.70, n.10, p.3178-3187, 1992.

PIMENTEL, J.J.O; SILVA, J.F.C.; VALADARES FILHO, S.C.V. et al. Efeito da suplementação protéica no valor nutritivo de silagens de milho e sorgo. Revista Brasileira de Zootecnia, v.27, n.5, p.1042-1049, 1998.

RANJIT, N.K.; KUNG JR., L. The effect of Lactobacillus buchneri, Lactobacillus plantarum, or a chemical preservative on the fermentation and aerobic stability of corn silage. Journal Dairy Science, v.83, n.3, p.526-535, 2000.

ROTZ, C.A.; MUCK, R.E. Changes in forage quality during harvest and storage. In: FAHEY JR., G.C.; MOSER, L.E.; MERTENS, D.R. et al. (Eds.) National conference on forage quality, evaluation and utilization. Madison: University of Nebraska, 1994 p.828-868.

SILVA, D.J. Análise de alimentos: métodos químicos e biológicos. Viçosa, MG: Universidade Federal de Viçosa, 1998. $165 \mathrm{p}$.

SILVA, J.M.; FEIJÓ, G.L.D.; THIAGO, L.R.L.S. et al. Desempenho animal e avaliação do potencial produtivo de forragens para ensilagem, por intermédio de diferentes fontes de suplementação nitrogenada. Revista Brasileira de Zootecnia, v.28, n.3, p.642-653, 1999.

TILLEY, J.M.A.; TERRY, R.A. A two stage techinique for the in vitro digestion of forage crops. Journal of British Society, v.18, n.1, p.104-111, 1963.

UNIVERSIDADE FEDERAL DE VIÇOSA - UFV. SAEG. Sistema de Análises Estatísticas e Genéticas. Viçosa, MG, 1998. (Versão 8.0).

Van SOEST, P.J. Nutritional ecology of the ruminant. 2.ed. Ithaca: Cornell University Press, 1994. 476p.

WOOLFORD, M.K. The silage fermentation. New York:Marcel Dekker, 1984. 350p.

ZAGO, C.P. Cultura de sorgo para produção de silagem de alto valor nutritivo. In: SIMPÓSIO SOBRE NUTRIÇÃO DE BOVINOS, 4., 1991, Piracicaba. Anais... Piracicaba: Fundação de Estudos Agrários “Luis de Queiroz”, 1991.p.169-217. 